\title{
Weight-bearing bones are more sensitive to physical exercise in boys than in girls during pre- and early puberty: a cross-sectional study
}

\author{
S. Kriemler • L. Zahner • J. J. Puder • \\ C. Braun-Fahrländer • C. Schindler • \\ N. J. Farpour-Lambert • M. Kränzlin • R. Rizzoli
}

Received: 10 January 2008 / Accepted: 4 March 2008 / Published online: 19 April 2008

(C) International Osteoporosis Foundation and National Osteoporosis Foundation 2008

\begin{abstract}
Summary We carried out a cross-section study of the sexspecific relationship between bone mineral content and physical activity at sites with different loading in pre- and early pubertal girls and boys. There was significant sensitivity of bone mineral content of the hip to physical exercise in boys, but not in girls.

Background Since little is known whether there are sex differences in sensitivity of bone to loading, we investigated sex differences in the cross-sectional association between measures of physical activity (PA) and bone mass and size in pre- and early pubertal children of both sexes.
\end{abstract}

S. Kriemler $(\bowtie) \cdot$ L. Zahner

Institute of Exercise and Health Sciences, University of Basel, Brüglingen 33,

4052 Basel, Switzerland

e-mail: susi.kriemler@unibas.ch

C. Braun-Fahrländer $\cdot$ C. Schindler

Institute of Social and Preventive Medicine, University of Basel,

Basel, Switzerland

J. J. Puder · M. Kränzlin

Division of Endocrinology, Diabetes and Clinical Nutrition,

University Hospital of Basel,

Basel, Switzerland

N. J. Farpour-Lambert

Department of Child and Adolescent Medicine,

University Hospitals of Geneva,

Geneva, Switzerland

R. Rizzoli

Service of Bone Diseases (WHO collaborating center for osteoporosis prevention), University Hospitals of Geneva, Geneva, Switzerland
Methods We measured bone mineral content/density (BMC/BMD) and fat-free mass (FFM) in 269 6- to 13year-old children from randomly selected schools by dualenergy X-ray absorptiometry. Physical activity (PA) was measured by accelerometers and lower extremity strength by a jump-and-reach test.

Results Boys $(n=128)$ had higher hip and total body BMC and BMD, higher FFM, higher muscle strength and were more physically active than girls $(n=141)$. Total hip BMC was positively associated with time spent in total and vigorous PA in boys $(r=0.20-0.33, p<0.01)$, but not in girls $(r=0.02-0.04, p=n s)$, even after adjusting for FFM and strength. While boys and girls in the lowest tertile of vigorous PA (22 min/day) did not differ in hip BMC (15.62 vs $15.52 \mathrm{~g}$ ), boys in the highest tertile (72 $\mathrm{min} /$ day) had significantly higher values than the corresponding girls (16.84 vs $15.71 \mathrm{~g}, p<0.05$ ).

Conclusions Sex differences in BMC during pre- and early puberty may be related to a different sensitivity of bone to physical loading, irrespective of muscle mass.

Keywords Bone $\cdot$ Children · Exercise $\cdot$ Muscle . Physical activity $\cdot$ Sex

\section{Introduction}

Preventive measures against osteoporosis begin in childhood and adolescence to ensure optimal peak bone mass which may reduce fracture risk later in life. Peak bone mass, the amount of bone accrued at the end of the pubertal spurt, is determined by genetic and environmental factors, 
including nutrition and physical exercise [1]. However, the full genetic potential determining peak bone mass is attained only if nutrition, physical activity (PA) and other lifestyle factors are optimized [2]. There is a relation between bone mass and muscle mass in both children and adults [3]. This observation has led to the concept that bone and muscle form an operational unit, with commensurate changes in both systems. On the other hand, others have stressed a major implication of other factors such as hormones and lifestyle, for instance PA, in the process of bone mass accumulation $[4,5]$.

Physically active individuals generally have higher muscle and bone mass, irrespective of age [6]. Apart from these cross-sectional results, high levels of PA were associated with higher bone mass in longitudinal [7] and intervention studies $[8,9]$. While muscle mass and muscle strength increase during growth, PA generally decreases, especially in girls. In prepubertal children, strength training does not induce muscle hypertrophy, despite a considerable strength increase [10]. Furthermore, since bone strength relative to muscle mass seems to increase during puberty, the sensitivity of the bone to adapt to mechanical strains may vary within the growth period $[1,8,11]$. Thus the association among PA, muscle strength and mass, and bone may change during puberty. Despite these complex interactions, most studies have taken muscle mass as a surrogate for PA and muscle strength, without any attempt to assess the direct association between PA and bone mass, independently from lean body mass. Hence, some data suggest that PA might be a predictor of bone mass independent of muscle mass and strength in elite athletes [5] or in preschool children [12].

There is controversy in the literature as to whether sex differences in bone mass, size or strength exist before and during early puberty. Higher density and strength of the radius $[13,14]$, equal bone geometry at femoral diaphysis $[15,16]$, higher femoral neck BMC and BMD $[12,17,18]$, or higher tibia bone strength [19] in prepubertal and early pubertal boys compared with girls have been reported [2]. When looking at sex-specific effects of PA, several animal studies have indeed demonstrated a lower sensitivity of bone to loading in the female animals [3, 20,21]. Likewise, boys' bones tended to respond more to PA than girls' bones before $[8,12,17,22,23]$ and during [23, 24] puberty, although this question of sex specificity was not a major focus of most studies.

We addressed the issue of sex differences in bone mass and size in early and prepubertal children and to what extent PA influences bone mass and size in children. We analyzed the baseline data of 6- to 13year-old children from randomly selected schools in terms of bone mineral mass at different skeletal sites, and objectively measured PA during daily life, fat-free mass, lower extremity muscle strength and Tanner stage. We hypothesized that:

1. There are sex differences in bone parameters even before puberty.

2. PA is a predictor of bone mass after adjusting for muscle mass in pre- and early pubertal boys and girls.

3. The effect of PA would be most pronounced at bone sites with high impact loading, i.e., the hip.

\section{Materials and methods}

\section{Participants and study design}

Study participants were recruited from schools participating in the KiSS study (="Kindersportstudie"), a randomized controlled trial of PA intervention at school [25]. Children were selected class-wise from 919 schools of two provinces with at least one first and one fifth grade class. In order to be representative of Switzerland, schools were additionally stratified for living area (rural vs urban) and ethnicity (at least $10-30 \%$ migrants). The current analysis was based on data collected in the baseline assessment. All measurements took place within 2 weeks. Within the population of 502 children available for baseline assessment, 376 (75\%) children participated in the bone measurements, 386 (77\%) children performed lower extremity strength testing, and 269 (54\%) underwent PA measurement by accelerometer. Five girls reported Tanner stage 4 or 5 and were excluded initially from the analysis due to their advanced maturation. Bone characteristics are given for the whole population $(n=371)$, while analyses relating PA to bone were performed with the sample with PA measured $(n=$ 269). Thirty-six children were not of Caucasian origin, i.e. Asians, Blacks, and Hispanics. Eighty percent of them represented a mixed population of different ethnicities. The study was approved by the local ethics committees. Written informed consent was provided by the children and at least one of their parents.

\section{Anthropometric and bone measurements}

Height and weight were measured in T-shirt, shorts, and bare feet using a Harpenden stadiometer (Holtain) with an accuracy of $0.1 \mathrm{~cm}$ and an electronic scale (Seca) with an accuracy of $0.1 \mathrm{~kg}$. Body composition and bone were measured using dual-energy X-ray absorptiometry (DXA; Hologic QDR-4500). Body composition was assessed by the three-compartment model, including fat mass, bone mineral content, and fat-free soft tissue. Bone mineral content (BMC, grams), bone area $\left(\mathrm{BA}, \mathrm{cm}^{2}\right)$, and areal bone mineral density (BMD, $\mathrm{g} / \mathrm{cm}^{2}$ ) were determined for 
total body, femoral neck, total hip, and L1-L4 vertebrae in the antero-posterior view. DXA was found to be reliable in children and sensitive to changes in fat and lean body mass [26]. The coefficient of variation of repeated measurements for the femur, lumbar spine, and total body, determined in young healthy adults, varies between 1 and $1.6 \%$ for BMD, and 0.3 and $3 \%$ for BMC and BA [27].

Physical activity and muscle strength

Physical activity was assessed by accelerometers (MTI/ CSA 7164, Actigraph) that have been validated for children and adolescents [28]. MTI accelerometers measure vertical displacements of the body. A piezoelectrical sensor measures the acceleration of the body in the vertical plane, i.e., the change in velocity over time and, as such, quantifies the extent and intensity of movement. The amplitude of this digital signal (raw counts) is determined by the system hardware including voltage, an amplification factor, and a conversion factor which changes the negative signals due to the negative accelerations of the body into positive ones. After these digital data reach the processor, they are filtered (for non-physiological motions defined as $<0.5$ and $>2.5 \mathrm{~Hz}$ ), summed up and integrated over the sampling interval or epoch time, which was set in this study at $1 \mathrm{~min}$. The arbitrary unit of "counts" is therefore an integrated measure of movement frequency and intensity based on the rate of acceleration of the body. The little instrument in the form and size of a matchbox was constantly worn around the hip over 7 days in early summer time. The accelerometer was attached firmly around the waist with an elastic belt and controlled by the investigator. Children were allowed to remove the accelerometer during sleep if it caused discomfort and during any type of contact with water such as swimming or showering. Data were included in the analysis if at least 4 full days (at least 3 weekdays and 1 weekend day) of measurements with a minimum of $12 \mathrm{~h}$ for the weekdays and $10 \mathrm{~h}$ for the weekends [28] were available. The minimal measurement time for the weekends was less, as most of the children slept $1-2 \mathrm{~h}$ more on these days. Times of $15 \mathrm{~min}$ or more of continuous zero values were considered as missing and were discarded. The variables analyzed were total PA (=sum of counts per waking time/period awake), and time spent in vigorous PA defined as sum of minutes per day with counts above 3,000. A cut-off of $4,200 \pm 840 \mathrm{cpm}$ has been found for jumping activities eliciting ground reaction forces of about 3.5 times body weight for 6- to 10-year-old children [29]. Considering the standard deviation of $840 \mathrm{cpm}$ and an intraclass coefficient of correlation of 0.91 in their reliability measurements, we set a cut-off of $3,000 \mathrm{cpm}$ to elicit ground reaction forces that have been shown to be efficient at increasing femur BMD in premenopausal women [30].
Lower extremity strength (LE strength) was assessed by a jump-and-reach test, in which the difference in height between standing (baseline) and after a maximal jump (endpoint) with arms maximally raised on both occasions was assessed. The difference between baseline and endpoint was measured in centimeters. The jump-and-reach test is validated in adults against power output on force plates [31], but no data for children are available. Since the jumping height not only depends on muscle mass and coordination, but is also a function of height, we expressed the jump-and-reach per body height in centimeters/centimeter. Each child had three attempts and the best one was used in the analysis.

\section{Questionnaires}

Parents of all children were asked about their ethnic background, educational level, and family history of osteoporosis. Included was also a sheet with a simple explanation and line drawings of the Tanner stages for the 5th grade children to rate their pubertal stage. Tanner stage was defined as prepubertal (Tanner stage 1) and early pubertal (Tanner stages 2 and 3) based on breast development for girls and pubic hair for boys. Self assessment of the Tanner stage has been validated and described as reasonably accurate in children of the western world [32]. Calcium intake was assessed by a validated questionnaire [33] adapted to the Swiss nutrition pattern where daily calcium intake was calculated in milligrams per day.

\section{Statistics}

Continuous variables were compared between groups by analysis of variance or $t$ test. Bonferroni correction was made for multiple comparisons. Associations of total hip, femoral neck, lumbar spine, and total body BMC and BMD with PA, LE strength (jump-and-reach), and FFM as surrogate for muscle mass were assessed using partial correlation coefficients, for boys and girls separately. The correlation between PA and BMC/BMD was progressively adjusted for height, age, Tanner stage, and then also for FFM and LE strength. Associations are reported by their correlation coefficient and their level of significance. The effect of VPA on total hip BMC adjusted for age, height, and Tanner stage was estimated separately for boys and girls using a general linear model including VPA, categorized into tertile classes. Posthoc comparisons were done using a Bonferroni adjusted $t$ test. Each association with covariates was tested for potential nonlinearity. The model was estimated separately for boys and girls. We created a further multiple regression model to evaluate the contribution of physical activity and LE muscle strength once height and muscle mass were controlled for. Separate 
models were created for each bone site and sex. Variables were entered into a three-step model:

1. Height and muscle mass

2. Physical activity and LE extremity strength

3. Tanner stage $(0=$ prepubertal, $1=$ early pubertal $)$, calcium intake, and ethnicity $(0=$ other than Caucasian, $1=$ Caucasian)

Analyses were performed using SPSS version 11.0 and Intercooled STATA version 8.

\section{Results}

Participant characteristics

Overall, boys had higher FFM and girls had higher fat mass, boys were more active and had higher LE strength as reflected by jump-and-reach test results than girls at any age (Table 1). PA decreased significantly from pre- to early puberty in both sexes. More girls than boys were in early puberty $(p<0.05)$. All bone variables increased significantly from pre- to early puberty. Those who did not have bone measurements were not different with respect to age, weight, height, and PA, and those who did not participate in accelerometer measurements were not different regarding PA assessed by questionnaire. Calcium intake was at average $969 \pm 374 \mathrm{mg} /$ day and was not different between girls and boys or between prepubertal and pubertal children. Hip and total body BMD, hip BMC, and bone area of the lumbar spine were higher in prepubertal boys than in girls. In early puberty hip BMD was higher in boys than girls. Bone results were not different when only those with PA assessments were considered. In this population divided up into VPA tertiles, there were no major differences in anthropometric data among all groups (Table 2). The only consistent difference was in the percentage of body fat, which was higher in girls.

\section{Relationship between hip BMC and PA}

In boys, hip BMC was significantly associated with PA (Table 3), even after incremental correction for age, height, and Tanner stage. When further adjusting BMC for muscle mass (FFM) and LE strength (jump-and-reach), the relation with PA remained statistically significant. In girls, hip BMC was not related to PA, irrespective of adjustments for FFM and LE strength (Table 3). Very similar results were obtained for hip BMD and also for BMC/BMD of the femoral neck (data not shown).

There was a direct relationship between hip BMC and VPA in boys, but not in girls (Fig. 1). Boys in the lowest tertile of VPA with on average 22 min of VPA per day had $7.3 \%$ lower hip BMC values than those in the highest tertile

Table 1 Participants' characteristics

\begin{tabular}{|c|c|c|c|c|}
\hline & \multicolumn{2}{|l|}{ Prepubertal } & \multicolumn{2}{|l|}{ Early pubertal } \\
\hline & Boys $(n=150)$ & Girls $(n=139)$ & Boys $(n=27)$ & Girls $(n=55)$ \\
\hline Age (years) & $9.1 \pm 2.1$ & $8.6 \pm 2.1$ & $11.4 \pm 0.7 * *$ & $11.2 \pm 0.6^{* * *}$ \\
\hline Weight $(\mathrm{kg})$ & $31.1 \pm 9.0$ & $29.3 \pm 8.2^{*}$ & $40.9 \pm 8.1^{* *}$ & $39.9 \pm 6.5 * * *$ \\
\hline Height $(\mathrm{cm})$ & $134.4 \pm 13.0$ & $131.2 \pm 12.1$ & $148.8 \pm 7.0^{* *}$ & $147.2 \pm 5.2 * * *$ \\
\hline Body fat $(\%)$ & $21.0 \pm 5.2$ & $25.4 \pm 5.7^{*}$ & $21.4 \pm 6.8$ & $26.4 \pm 5.2 *, * * *$ \\
\hline Fat-free mass $(\mathrm{kg})$ & $23.6 \pm 6.1$ & $20.9 \pm 5.64 *$ & $30.8 \pm 4.9 * *$ & $27.9 \pm 3.4 * * * *$ \\
\hline Jump and reach $(\mathrm{cm})$ & $24.9 \pm 6.7$ & $22.5 \pm 6.4^{*}$ & $31.0 \pm 6.2^{* *}$ & $25.9 \pm 5.8 * * * *$ \\
\hline Total activity (counts $* 10^{4} /$ day) & $680 \pm 157$ & $570 \pm 112 *$ & $598 \pm 169 * *$ & $495 \pm 186^{*}, * * *$ \\
\hline VPA ( $\min >3,000$ counts $)$ & $58 \pm 22$ & $36 \pm 16^{*}$ & $53 \pm 23$ & $32 \pm 22 *$ \\
\hline TB area $\left(\mathrm{cm}^{2}\right)$ & $1,328 \pm 186$ & $1,293 \pm 152$ & $1,520 \pm 148^{* *}$ & $1,492 \pm 92 * * *$ \\
\hline $\mathrm{TB} \mathrm{BMC}(\mathrm{g})$ & $1,056 \pm 261$ & $974 \pm 217 *$ & $1,310 \pm 179 * *$ & $1,248 \pm 146^{* * *}$ \\
\hline TB BMD $\left(\mathrm{g} / \mathrm{cm}^{2}\right)$ & $0.785 \pm 0.091$ & $0.745 \pm 0.083 *$ & $0.859 \pm 0.048^{* *}$ & $0.835 \pm 0.055^{* * *}$ \\
\hline LS area $\left(\mathrm{cm}^{2}\right)$ & $38.4 \pm 5.4$ & $36.2 \pm 4.8^{*}$ & $44.1 \pm 4.2 * *$ & $42.0 \pm 3.9 * * *$ \\
\hline $\operatorname{LS}$ BMC $(g)$ & $22.7 \pm 6.1$ & $21.2 \pm 4.8$ & $28.8 \pm 4.6^{* *}$ & $28.7 \pm 5.0^{* * *}$ \\
\hline $\operatorname{LS}$ BMD $\left(\mathrm{g} / \mathrm{cm}^{2}\right)$ & $0.584 \pm 0.091$ & $0.581 \pm 0.080$ & $0.651 \pm 0.065^{* *}$ & $0.682 \pm 0.082 * * *$ \\
\hline Hip area $\left(\mathrm{cm}^{2}\right)$ & $21.0 \pm 5.7$ & $19.9 \pm 4.8$ & $26.9 \pm 4.1^{* *}$ & $26.4 \pm 2.7^{* * *}$ \\
\hline Hip BMC (g) & $15.2 \pm 5.8$ & $13.2 \pm 4.4^{*}$ & $20.9 \pm 4.5^{* *}$ & $19.1 \pm 3.3^{* * *}$ \\
\hline Hip BMD $\left(\mathrm{g} / \mathrm{cm}^{2}\right)$ & $0.707 \pm 0.098$ & $0.654 \pm 0.083^{*}$ & $0.775 \pm 0.074 * *$ & $0.719 \pm 0.078^{* * *}$ \\
\hline
\end{tabular}

Values are means $\pm \mathrm{SD}$

VPA, vigorous physical activity in minutes above a cut-off of 3,000 counts; Area, bone area; BMC, bone mineral content; BMD, bone mineral density; TB, total body; LS, lumbar spine; Hip, total hip

Boys/girls of same pubertal stage: ${ }^{*} p<0.05$, boys pre-early puberty: $* * p<0.05$, girls pre-early puberty: $* * * p<0.05$ 
Table 2 Participants' characteristics based on vigorous physical activity tertiles

\begin{tabular}{|c|c|c|c|c|c|c|c|c|}
\hline & \multirow{2}{*}{\multicolumn{2}{|c|}{ All }} & \multicolumn{6}{|l|}{ VPA tertiles } \\
\hline & & & \multicolumn{2}{|l|}{ Low } & \multicolumn{2}{|l|}{ Moderate } & \multicolumn{2}{|l|}{ High } \\
\hline & Boys $(n=128)$ & Girls $(n=141)$ & Boys $(n=21)$ & Girls $(n=68)$ & Boys $(n=39)$ & Girls $(n=50)$ & Boys $(n=71)$ & Girls $(n=20)$ \\
\hline Age (years) & $9.7 \pm 2.1$ & $9.7 \pm 2.1$ & $9.4 \pm 2.3$ & $9.7 \pm 2.1$ & $9.9 \pm 1.9$ & $9.4 \pm 2.1$ & $9.7 \pm 2.1$ & $10.4 \pm 1.6$ \\
\hline Weight (kg) & $33.2 \pm 9.6$ & $34.0 \pm 9.4$ & $33.0 \pm 12.8$ & $34.8 \pm 9.7$ & $34.2 \pm 8.2$ & $31.2 \pm 8.6$ & $32.6 \pm 9.5$ & $38.5 \pm 7.9$ \\
\hline Height (cm) & $137.8 \pm 13.0$ & $137.9 \pm 12.4$ & $134.8 \pm 14.0$ & $139.7 \pm 10.9$ & $135.4 \pm 12.6$ & $137.6 \pm 13.8$ & $142.9 \pm 8.0$ & \\
\hline Body fat $(\%)$ & $21.0 \pm 5.6$ & $26.6 \pm 5.6$ & $23.0 \pm 6.0$ & $26.6 \pm 5.6$ & $22.3 \pm 5.9 * *$ & $23.9 \pm 5.6$ & $19.8 \pm 5.1 * * *$ & $26.6 \pm 3.4 * * * *$ \\
\hline Fat-free mass $(\mathrm{kg})$ & $25.0 \pm 6.4$ & $24.0 \pm 5.9$ & $24.0 \pm 8.1$ & $24.1 \pm 6.0$ & $25.4 \pm 5.0$ & $24.7 \pm 5.6$ & $25.1 \pm 6.7$ & $26.8 \pm 5.0$ \\
\hline Tanner stage $(1 />1)(n)$ & $107 / 21$ & $96 / 45$ & $14 / 5$ & $42 / 28$ & $34 / 5$ & $40 / 12$ & $59 / 11$ & $14 / 5$ \\
\hline Jump and reach $(\mathrm{cm})$ & $26.0 \pm 7.2$ & $24.1 \pm 6.1$ & $24.4 \pm 9.9$ & $23.3 \pm 6.2^{*}$ & $25.4 \pm 6.1$ & $24.6 \pm 6.2$ & $26.7 \pm 6.9$ & $25.9 \pm 4.7$ \\
\hline
\end{tabular}

Values are mean $\pm \mathrm{SD}$

VPA, vigorous physical activity ( $>3,000$ counts)

* Significantly different from boys with high VPA

**Significantly different from girls with low VPA

$* * *$ Significantly different from all girls

$* * * *$ Significantly different between boys and girls of high VPA

with on average $72 \mathrm{~min}$ of VPA $(p<0.001)$, while there was no significant difference in hip BMC among girls in the lowest and highest tertile (15.52 vs $15.71 \mathrm{~g}$ ). Boys and girls in the lowest tertile of VPA did not differ in hip BMC (15.62 vs $15.52 \mathrm{~g}$ ), while boys in the highest tertile showed significantly higher hip BMC than the corresponding girls (16.84 vs $15.71, p<0.01)$. Correcting for Tanner stage and/ or FFM or replacing BMC with BMD did not change the association between hip bone parameters and PA.

The association of BMC/areal BMD with VPA and LE strength (jump-and-reach) was significant at weight bearing sites such as total hip (Table 4) and femoral neck (data not shown) in boys, but not in girls. In contrast there was no association of lumbar spine and total body BMC with PA when separated by sex. BMC and FFM were significantly related at all sites and in both sexes.

Determinants of bone mineral content

In a linear regression model we tried to find the best predictors of hip BMC for girls and boys separately
(Table 5). Variables such as age, height, weight, fat-free mass, fat mass, physical activity, jump-and-reach, Tanner stage, calcium intake, and ethnicity were entered into the initial model. Since weight, fat mass, Tanner stage, calcium intake, and ethnicity did not explain any further variance after including height, fat-free mass, physical activity, and jump-and-reach for both sexes, these variables were omitted from the model. Height and fat-free mass explained most of the variance of BMC at all sites and in both sexes ranging from 79 to $90 \%$. While average activity and jump-andreach accounted for an additional $1.8-2.8 \%$ of the variability of BMC in boys, this was not the case in girls. As an example, increasing $3 \mathrm{~cm}$ (about 10\%) in the jump-andreach test and adding $5 \mathrm{~min}$ of VPA (about 10\%), would result in a $3 \%$ increase in hip BMC in boys.

\section{Discussion}

The strength of the present study lies in the large, randomly selected study sample of normal children and in the

Table 3 Association between hip BMC and physical activity in boys and girls

\begin{tabular}{|c|c|c|c|c|c|c|}
\hline \multirow[t]{2}{*}{ BMC adjusted for } & \multicolumn{2}{|c|}{ Vigorous physical activity } & \multicolumn{2}{|c|}{ Jump-and-reach } & \multicolumn{2}{|c|}{ Fat-free mass } \\
\hline & Boys & Girls & Boys & Girls & Boys & Girls \\
\hline Age, height & $0.170^{*}$ & 0.083 & $0.305 * * *$ & 0.064 & $0.529 * * *$ & $0.573 * * *$ \\
\hline Age, height, Tanner & $0.169 *$ & 0.074 & $0.295 * * *$ & -0.02 & $0.522 * * *$ & $0.573 * * *$ \\
\hline Age, height, Tanner, fat-free mass & $0.206^{*}$ & 0.077 & $0.253 * *$ & -0.046 & & \\
\hline Age, height, Tanner, fat-free mass, jump and reach & $0.194 *$ & -0.084 & & & & \\
\hline
\end{tabular}

Partial correlation analysis between bone mineral density (BMD) of the hip and measurements of physical activity, muscle mass, and lower extremity strength

$* p<0.05, * * p<0.01, * * * p<0.001$ 

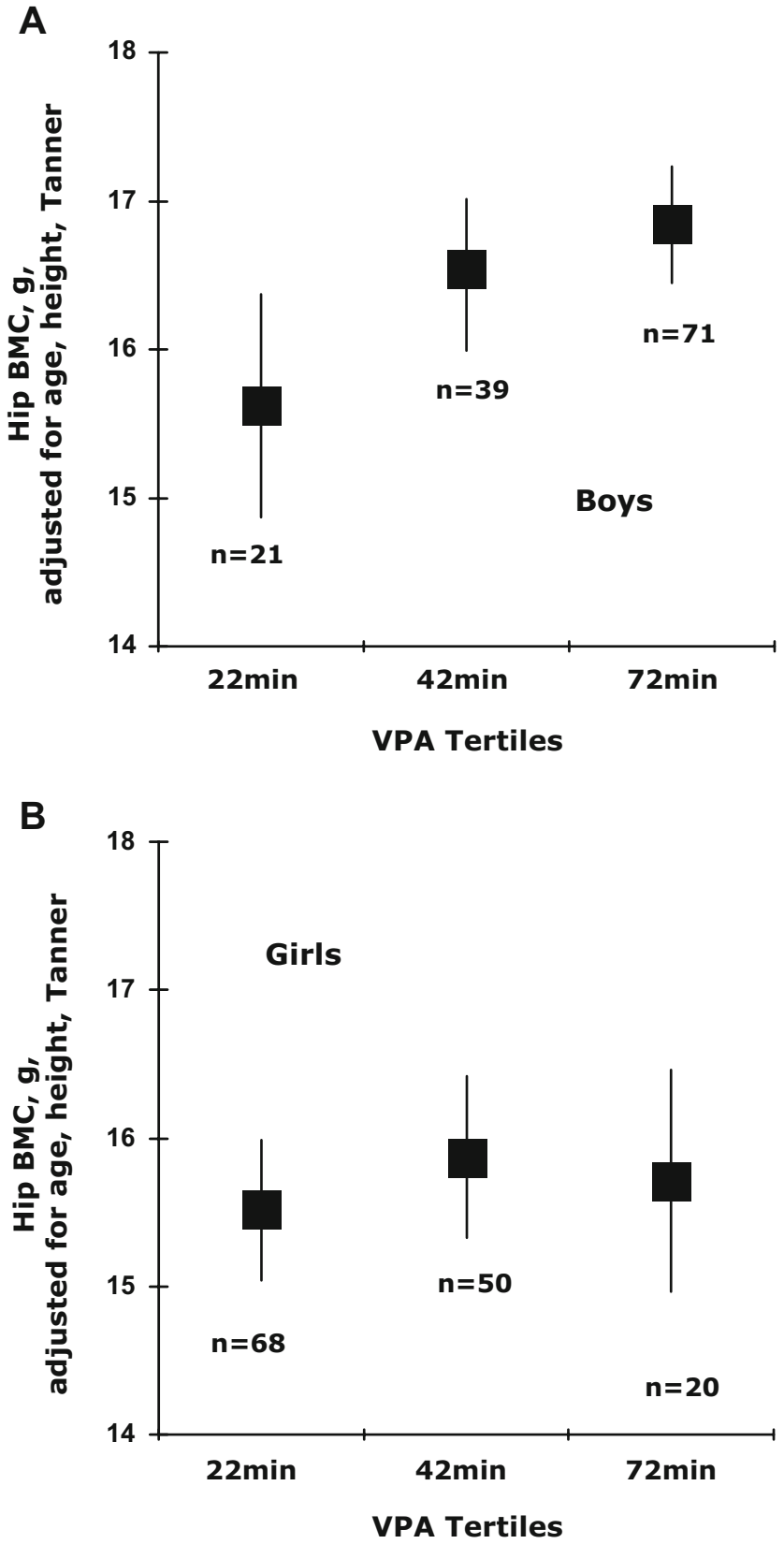

Fig. 1 Bone mineral content (BMC) of the hip by vigorous physical activity (VPA) tertiles for $\mathbf{a}$ boys and $\mathbf{b}$ girls separately. Pairwise $t$ test comparisons (with Bonferroni corrections) were done among genders and VPA tertiles after correction for age, height, fat-free mass, and Tanner stage. Values are means $\pm 95 \% \mathrm{CI}$

assessment of PA of daily life by objective means. As such, this cross-sectional study assessed three main questions: first, whether sex differences in bone mass and in the association between bone mass and PA exist in early and prepuberty; second, whether there is an independent effect of PA on bone; and third, whether there is a site specificity of PA on bone. We found a difference in BMC and BMD in favor of the boys that was already present before puberty. The positive association of total hip BMC and BMD with measured PA was apparent only in boys and explained 1.8$2.8 \%$ of variability after controlling for size and muscle mass. The influence of PA on BMC and BMD was site specific and occurred mainly in load-bearing bones such as the hip and femoral neck, but not in the lumbar spine and total body.

Sex differences in various bone parameters during prepuberty have been described, but this is still a controversial issue [12, 15-17, 22, 24, 34, 35]. It is difficult to compare results among the studies because of different measurement sites, various techniques and analysis procedures used. Boys in our study showed higher hip and total body BMC and BMD than girls even before puberty. This is in accordance with previous studies [12, 35]. Bone areas at these sites were not significantly different between the sexes. In boys, BMC was also significantly higher at sites with higher BMD, i.e. for hip and total body. Based on the low number of children in the pubertal group we cannot generalize these findings. Differences arising between studies are likely due to the fact that body size, composition, and biological age have not adequately been taken into account. Indeed, when BMC was adjusted for height and FFM, there were no more sex differences in BMC for both maturational groups. However, when hip BMD was adjusted for height and FFM, it remained significantly higher in prepubertal boys. It is possible, that those studies that did not find a difference in bone parameters between the sexes included populations that were less physically active than most of our children. Indeed, when we look at the children of the lowest tertile of PA in our study, there were no sex differences in hip BMC and BMD.

The positive association between children's bone mass and PA has been reported in cross-sectional [17, 36], longitudinal [17, 37], and intervention (for review see [38]) studies. These results support the current view that exercise is an important determinant of bone mass not only in adult athletes, but also in normal children. Our data are crosssectional and causality cannot be established. However, there are several reasons in favor of PA accounting for at least a part of the increased hip BMC and BMD in the boys compared with the girls. First, PA was objectively measured by accelerometers over the period of 4-7 days during regular life activities. These motion sensors measure accelerations of the body in the vertical plane, which is an elegant surrogate of impact loading of the body. Second, boys and girls in the lowest tertile of VPA did not differ in hip BMC and BMD, suggesting that the boys who do not exert impact on their bones have similar BMC and BMDs to the girls with low levels of VPA. Third, boys in the highest tertile of VPA showed significantly higher BMC and BMDs of the hip than their inactive counterparts, but also compared with the highly and similarly active girls. These findings suggest that boys' bones are more sensitive 
Table 4 Sex and site specificity of physical activity and bone mineral density

\begin{tabular}{lllll}
\hline & & VPA & Jump-and-reach & FFM \\
\hline Hip BMC & Boys & $0.244^{* *}$ & $0.295^{* * *}$ & $0.552^{* * *}$ \\
& Girls & 0.101 & 0.02 & $0.524^{* * *}$ \\
Hip BMD & Boys & $0.238^{* *}$ & $0.227^{* *}$ & $0.380^{* * *}$ \\
& Girls & 0.143 & $0.190^{*}$ & $0.439^{* * * *}$ \\
LS BMC & Boys & 0.166 & -0.051 & $0.416^{* * *}$ \\
& Girls & 0.115 & 0.119 & $0.346^{* * *}$ \\
LS BMD & Boys & 0.077 & -0.07 & $0.331^{* * *}$ \\
& Girls & 0.118 & $0.222^{*}$ & $0.530^{* * *}$ \\
TB BMC & Boys & 0.155 & -0.034 & $0.524^{* * *}$ \\
& Girls & 0.132 & $0.183^{*}$ & $0.247^{* *}$ \\
TB BMD & Boys & 0.162 & 0.011 & $0.449 * * *$ \\
& Girls & 0.158 & \\
\hline
\end{tabular}

Partial correlation coefficients for bone mineral density (BMD) of the hip, lumbar spine (LS) and total body (TB) vs vigorous physical activity (VPA); lower extremity strength (jump-and-reach test), and fat-free mass (FFM) after adjustment for age, height and Tanner stage $n($ boys $)=122 ; n($ girls $)=132 ; * \mathrm{p}<0.05, * * \mathrm{p}<0.01, * * * \mathrm{p}<0.001$

to loading than girls' bones. One could argue that confounding variables other than PA were responsible for the difference in bone parameters, a problem often faced in cross-sectional studies. The fact that after adjusting BMC and BMD for major factors influencing bone accretion during growth (i.e., age, height, Tanner stage, and surrogates of muscle mass and strength), PA persisted as a significant determinant of hip bone parameters in boys, could serve as indirect evidence of the role of PA. Of note is also that other potentially influencing factors such as school transportation, food intake, and media use were not different between boys and girls. The fact that neither boys nor girls showed an association between PA and bone mass at the lumbar spine and total body, where impact loading is less, further supports our hypothesis of a real association between PA and bone parameters.

Specific sex differences in bone sensitivity regarding PA are nearly absent in the literature, although there is some evidence from animal studies [21, 39]. A large crosssectional study found differences in bone density and bone strength in prepubertal children in favor of the boys with differences largely explained by muscle mass and bone length [19]. Interestingly, bivariate analysis found that a questionnaire-based PA score and the bone parameters were significantly related in boys, but not in girls, and an increase in PA in boys from one quintile to the next highest was associated with a $10 \%$ increase in a bone strength index of the tibia, while this was not the case in girls. Other

Table 5 Multiple regression models for BMC variables for total body, lumbar spine and hip in girls and boys

\begin{tabular}{|c|c|c|c|c|c|c|c|}
\hline \multirow[t]{2}{*}{ Dependent variable } & \multirow[t]{2}{*}{ Independent variable } & \multicolumn{3}{|l|}{ Boys } & \multicolumn{3}{|l|}{ Girls } \\
\hline & & $\beta(\mathrm{SE})$ & $p$ value & $\mathrm{R}^{2}$ & $\beta(\mathrm{SE})$ & $p$ value & $\mathrm{R}^{2}$ \\
\hline \multirow[t]{4}{*}{ TB BMC } & Height & $18.4(0.6)$ & $<0.000$ & 0.892 & $18.4(0.7)$ & $<0.000$ & 0.894 \\
\hline & FFM & $23.2(2.9)$ & $<0.000$ & & $31.7(2.4)$ & $<0.000$ & \\
\hline & Jump-and-reach & $3.0(1.2)$ & $<0.05$ & $0.901 *$ & $0.96(1.17)$ & $\mathrm{ns}$ & \\
\hline & Activity & $0.09(0.03)$ & $<0.01$ & & $-0.000(0.05)$ & $\mathrm{ns}$ & \\
\hline \multirow[t]{4}{*}{ LS BMC } & Height & $0.40(0.02)$ & $<0.000$ & 0.788 & $0.46(0.02)$ & $<0.001$ & 0.807 \\
\hline & FFM & $0.62(0.09)$ & $<0.000$ & & $0.98(0.09)$ & $<0.001$ & \\
\hline & Jump-and-reach & $0.07(0.04)$ & $\mathrm{ns}$ & $0.806^{*}$ & $-0.03(0.04)$ & $\mathrm{ns}$ & \\
\hline & Activity & $0.002(0.001)$ & $<0.05$ & & $-0.001(0.001)$ & $\mathrm{ns}$ & \\
\hline \multirow[t]{4}{*}{ Hip BMC } & Height & $0.41(0.01)$ & $<0.000$ & 0.879 & $0.37(0.01)$ & $<0.000$ & 0.878 \\
\hline & FFM & $0.59(0.07)$ & $<0.000$ & & $0.68(0.05)$ & $<0.000$ & \\
\hline & Jump-and-reach & $0.10(0.03)$ & $<0.001$ & $0.883^{*}$ & $0.02(0.03)$ & $\mathrm{ns}$ & \\
\hline & Activity & $0.002(0.001)$ & $<0.05$ & & $-0.000(0.000)$ & ns & \\
\hline
\end{tabular}

$\beta$, estimated regression coefficient; SE, standard error; TB BMC, total body bone mineral content; LS BMC, lumber spine bone mineral content; Hip BMC, bone mineral content of the hip; Total activity in counts*104/day, FFM, fat-free mass from DXA

$* \mathrm{R}^{2}$ change significant at $p<0.05$ 
cross-sectional studies described similar findings, i.e. a significant association between various bone parameters with a PA measure in boys, but not in girls [22, 34]. Janz et al. [17] looked at the longitudinal influence of PA (measured by accelerometers) on bone parameters in prepubertal children between the age of 5 and 8 years. Maintaining higher levels of PA from 5 to 8 years was predictive of higher levels of femoral neck BMC in boys, but not in girls. Even intervention studies gave evidence that girls did not increase femoral neck BMD [8] with exercise interventions lasting 7 months. However, when looking at all well-controlled intervention studies in children, most of them - performed in girls of various maturation levels - showed a significant exercise effect on bone accrual [38]. Interestingly, prepubertal boys, but not pre- and early pubertal girls, did respond to a 16-month specific exercise intervention with increased bone strength index of the tibia measured by pQCT [23]. There was less variability in VPA in prepubertal girls compared with boys, which may have led to less power in the analysis. Yet, it is also possible that the different height and weight (although not significant) in favor of the boys could have influenced our results. There is also a chance that our girls did not load their bones to the same extent, or that their loading modality was different and thus less specific. In addition, estrogens or other female-specific traits may inhibit mechanosensitivity to loading, as described in growing rats [3] or humans [11].

That women are more prone to osteoporotic fractures than men is partly explained by growth-related origins of structural abnormalities [2]. Family and twin studies have documented that up to $80 \%$ of the variability in peak bone mass is determined genetically [40]. However, genetics cannot be changed and from a public health perspective it is of utmost importance to find strategies to maximize bone mass and strength, even with small steps in the right direction. Thus, even a change of $1.8-2.8 \%$ in bone mass by loading may be relevant. Growth is the most sensitive time to modify mass or geometry of the skeleton through exercise [1]. Incontrovertible evidence comes from young racquet-ball players who show significantly higher areal BMD in the playing arm compared with the nonplaying arm [5, 11, 41]. Since muscle mass, strength, and PA are modifiable determinants of bone mass during growth [42], it is important to know their contribution in influencing bone mass. Height and FFM explained $79-90 \%$ of the variance in BMC at the different sites. Although small, PA and LE strength added a significant contribution to the model in boys, but not in girls. Age, weight, fat mass, calcium intake, and Tanner stage did not significantly contribute to the model. An increase of $10 \%$ in PA and strength, corresponding to $10 \mathrm{~min}$ of VPA per day and a $3-\mathrm{cm}$ increase in a vertical jump would increase hip BMC by $3 \%$. This is practicable and relevant, since epidemiological studies suggest that an increase in peak bone mass of $10 \%$ would delay the onset of osteoporosis by 13 years and reduce fractures after the menopause by $50 \%$ [43]. Whether the osteogenic response to physical activity or loading is genetically determined as well remains an open field of research.

We are aware of some limitations of our study. Maturational stage was assessed with Tanner staging, which is known to have limitations in appropriately capturing differences in speed and timing of growth between girls and boys [44]. By grouping the children into pre- (Tanner stage 1) and early puberty (Tanner stages 2 and 3) we tried to overcome this limitation. There is a need to validate the motion sensors for impact loading of the bone. From a biomechanical viewpoint and some evidence from the literature [29, 30], it makes sense to assume that the counts as expression of the vertical displacement of the body are somehow correlated to the amount of ground reaction forces, at least in a semiquantitative way. Motion sensors poorly capture PA performed in low motion or when the body is carried by a vehicle. Since bone responds to any type of force application with bending, torsion or impact loading, the motion sensors might not capture all activities of daily life. Yet, some elegant prospective data in premenopausal women demonstrate promising results showing that the intensity of exercise assessed by accelerometers was associated with increases in BMD at various body sites $[30,45]$. The measurement of lower extremity strength by the jump-and-reach test is validated for adults [31], but not for children. However, even when the jumpand-reach test was corrected for height and/or body weight, which are important determinants of power in the adult population, our results did not change. Appropriate equations for children should be developed so that the jumpand-reach test can be used to estimate muscle force and power without the need for a power plate. Nowadays, the DXA method is used as the gold standard for the diagnosis of osteoporosis, but we are well aware of the limitations inherent in the two-dimensional measurement technique, with its inability to accurately detect changes in bone geometry.

\section{Conclusion}

In conclusion, our cross-sectional study showed a sexrelated dose-response of bone to PA in pre- and early pubertal children. The association between BMC/BMD and PA remained after adjustment for FFM and muscle strength. Bone adaptation to impact loading was site-specific and was mostly detectable at the hip. 
Acknowledgements We thank all the children, parents, and teachers who volunteered to participate in this study. We thank the foundation AETAS, Switzerland, for the use of their DXA bus, and we greatly appreciate the help of Giulio Conicella and Chantal Genet for their competent help with the bone measurements. We also thank the Federal Council of Sports, Magglingen, Switzerland, for their financial support of the study.

\section{Conflicts of interest None.}

\section{References}

1. Seeman E (2002) An exercise in geometry. J Bone Miner Res $17: 373-380$

2. Seeman E (2002) Pathogenesis of bone fragility in women and men. Lancet 359:1841-1850

3. Jarvinen TL, Kannus P, Pajamaki I, Vuohelainen T, Tuukkanen J, Jarvinen M, Sievanen H (2003) Estrogen deposits extra mineral into bones of female rats in puberty, but simultaneously seems to suppress the responsiveness of female skeleton to mechanical loading. Bone 32:642-651

4. Ducher G, Courteix D, Meme S, Magni C, Viala JF, Benhamou CL (2005) Bone geometry in response to long-term tennis playing and its relationship with muscle volume: a quantitative magnetic resonance imaging study in tennis players. Bone 37 : 457-466

5. Daly RM, Saxon L, Turner CH, Robling AG, Bass SL (2004) The relationship between muscle size and bone geometry during growth and in response to exercise. Bone 34:281-287

6. Kontulainen SA, Hughes JM, Macdonald HM, Johnston JD (2007) The biomechanical basis of bone strength development during growth. Med Sport Sci 51:13-32

7. Matthews BL, Bennell KL, McKay HA, Khan KM, Baxter-Jones AD, Mirwald RL, Wark JD (2006) Dancing for bone health: a 3 -year longitudinal study of bone mineral accrual across puberty in female non-elite dancers and controls. Osteoporos Int 17(7): 1043-1054

8. Petit MA, McKay HA, MacKelvie KJ, Heinonen A, Khan KM, Beck TJ (2002) A randomized school-based jumping intervention confers site and maturity-specific benefits on bone structural properties in girls: a hip structural analysis study. J Bone Miner Res 17:363-372

9. MacKelvie KJ, Petit MA, Khan KM, Beck TJ, McKay HA (2004) Bone mass and structure are enhanced following a 2-year randomized controlled trial of exercise in prepubertal boys. Bone 34:755-764

10. Blimkie CJ (1993) Resistance training during preadolescence. Issues and controversies. Sports Med 15:389-407

11. Kannus P, Haapasalo H, Sankelo M, Sievanen H, Pasanen M, Heinonen A, Oja P, Vuori I (1995) Effect of starting age of physical activity on bone mass in the dominant arm of tennis and squash players. Ann Intern Med 123:27-31

12. Janz KF, Burns TL, Levy SM, Torner JC, Willing MC, Beck TJ, Gilmore JM, Marshall TA (2004) Everyday activity predicts bone geometry in children: the Iowa bone development study. Med Sci Sports Exerc 36:1124-1131

13. Hasselstrom H, Karlsson KM, Hansen SE, Gronfeldt V, Froberg K, Andersen LB (2006) Sex differences in bone size and bone mineral density exist before puberty. The Copenhagen School Child Intervention Study (CoSCIS). Calcif Tissue Int 79:7-14

14. Neu CM, Rauch F, Manz F, Schoenau E (2001) Modeling of cross-sectional bone size, mass and geometry at the proximal radius: a study of normal bone development using peripheral quantitative computed tomography. Osteoporos Int 12:538-547
15. Gilsanz V, Kovanlikaya A, Costin G, Roe TF, Sayre J, Kaufman F (1997) Differential effect of gender on the sizes of the bones in the axial and appendicular skeletons. J Clin Endocrinol Metab 82:1603-1607

16. Loro ML, Sayre J, Roe TF, Goran MI, Kaufman FR, Gilsanz V (2000) Early identification of children predisposed to low peak bone mass and osteoporosis later in life. J Clin Endocrinol Metab 85:3908-3918

17. Janz KF, Gilmore JM, Burns TL, Levy SM, Torner JC, Willing MC, Marshall TA (2006) Physical activity augments bone mineral accrual in young children: the Iowa Bone Development study. J Pediatr 148:793-799

18. McKay HA, Petit MA, Khan KM, Schutz RW (2000) Lifestyle determinants of bone mineral: a comparison between prepubertal Asian- and Caucasian-Canadian boys and girls. Calcif Tissue Int 66:320-324

19. Macdonald HM, Kontulainen SA, Mackelvie-O'Brien KJ, Petit MA, Janssen P, Khan KM, McKay HA (2005) Maturity- and sexrelated changes in tibial bone geometry, strength and bone-muscle strength indices during growth: a 20 -month pQCT study. Bone 36:1003-1011

20. Mosley JR, Lanyon LE (2002) Growth rate rather than gender determines the size of the adaptive response of the growing skeleton to mechanical strain. Bone 30:314-319

21. Wallace JM, Rajachar RM, Allen MR, Bloomfield SA, Robey PG, Young MF, Kohn DH (2007) Exercise-induced changes in the cortical bone of growing mice are bone- and gender-specific. Bone 40:1120-1127

22. Jones G, Dwyer T (1998) Bone mass in prepubertal children: gender differences and the role of physical activity and sunlight exposure. J Clin Endocrinol Metab 83:4274-4279

23. Macdonald HM, Kontulainen SA, Khan KM, McKay HA (2007) Is a school-based physical activity intervention effective for increasing tibial bone strength in boys and girls? J Bone Miner Res 22:434-446

24. Sundberg M, Gardsell P, Johnell O, Karlsson MK, Ornstein E, Sandstedt B, Sernbo I (2001) Peripubertal moderate exercise increases bone mass in boys but not in girls: a population-based intervention study. Osteoporos Int 12:230-238

25. Zahner L, Puder JJ, Roth R, Schmid M, Guldimann R, Puhse U, Knopfli M, Braun-Fahrlander C, Marti B, Kriemler S (2006) A school-based physical activity program to improve health and fitness in children aged 6-13 years ("Kinder-Sportstudie KISS"): study design of a randomized controlled trial [ISRCTN15360785]. BMC Public Health 6:147

26. Gutin B, Owens S (1999) Role of exercise intervention in improving body fat distribution and risk profile in children. Am J Hum Biol 11:237-247

27. Bonjour JP, Chevalley T, Ammann P, Slosman D, Rizzoli R (2001) Gain in bone mineral mass in prepubertal girls 3.5 years after discontinuation of calcium supplementation: a follow-up study. Lancet 358:1208-1212

28. Freedson P, Pober D, Janz KF (2005) Calibration of accelerometer output for children. Med Sci Sports Exerc 37:S523-S530

29. Janz K, Rao S, Baumann HJ, Schultz JL (2003) Measuring children's vertical ground reaction forces with accelerometry during walking, running, and jumping: the Iowa Bone Development Study. Pediatr Exerc Sci 15:34-43

30. Jamsa T, Vainionpaa A, Korpelainen R, Vihriala E, Leppaluoto J (2006) Effect of daily physical activity on proximal femur. Clin Biomech (Bristol, Avon) 21:1-7

31. Lara AJ, Abian J, Alegre LM, Jimenez L, Aguado X (2006) Assessment of power output in jump tests for applicants to a sports sciences degree. J Sports Med Phys Fitness 46:419-424

32. Duke PM, Litt IF, Gross RT (1980) Adolescents' self-assessment of sexual maturation. Pediatrics 66:918-920 
33. Molgaard C, Sandstorm B, Michaelsen KF (1998) Evaluation of a food frequency questionnaire for assessing of calcium, protein and phosphorus intakes in children and adolescents. Scand J Nutr $42: 2-5$

34. Molgaard C, Thomsen BL, Michaelsen KF (2001) The influence of calcium intake and physical activity on bone mineral content and bone size in healthy children and adolescents. Osteoporos Int 12:887-894

35. Forwood MR, Bailey DA, Beck TJ, Mirwald RL, Baxter-Jones AD, Uusi-Rasi K (2004) Sexual dimorphism of the femoral neck during the adolescent growth spurt: a structural analysis. Bone 35:973-981

36. Iuliano-Burns S, Stone J, Hopper JL, Seeman E (2005) Diet and exercise during growth have site-specific skeletal effects: a co-twin control study. Osteoporos Int 16:1225-1232

37. Forwood MR, Baxter-Jones AD, Beck TJ, Mirwald RL, Howard A, Bailey DA (2006) Physical activity and strength of the femoral neck during the adolescent growth spurt: a longitudinal analysis. Bone 38:576-583

38. Hughes JM, Novotny SA, Wetzsteon RJ, Petit MA (2007) Lessons learned from school-based skeletal loading intervention trials: putting research into practice. Med Sport Sci 51:137-158
39. Jarvinen TL, Pajamaki I, Sievanen H, Vuohelainen T, Tuukkanen J, Jarvinen M, Kannus P (2003) Femoral neck response to exercise and subsequent deconditioning in young and adult rats. J Bone Miner Res 18:1292-1299

40. Peacock M, Turner CH, Econs MJ, Foroud T (2002) Genetics of osteoporosis. Endocr Rev 23:303-326

41. Bass SL, Saxon L, Daly RM, Turner CH, Robling AG, Seeman E, Stuckey S (2002) The effect of mechanical loading on the size and shape of bone in pre-, peri-, and postpubertal girls: a study in tennis players. J Bone Miner Res 17:2274-2280

42. Frost HM, Schonau E (2000) The "muscle-bone unit" in children and adolescents: a 2000 overview. J Pediatr Endocrinol Metab 13:571-590

43. Cummings SR, Melton LJ (2002) Epidemiology and outcomes of osteoporotic fractures. Lancet 359:1761-1767

44. Sherar LB, Baxter-Jones AD, Mirwald RL (2004) Limitations to the use of secondary sex characteristics for gender comparisons. Ann Hum Biol 31:586-593

45. Vainionpaa A, Korpelainen R, Vihriala E, Rinta-Paavola A, Leppaluoto J, Jamsa T (2006) Intensity of exercise is associated with bone density change in premenopausal women. Osteoporos Int 17:455-463 